TI 2011-118/3

Tinbergen Institute Discussion Paper

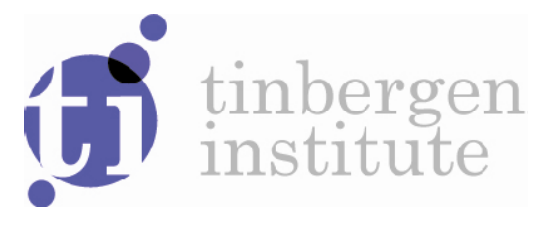

\title{
Second-degree Price Discrimination and Inter-group Effects in Airline Routes between European Cities
}

\author{
Marco Alderighir \\ Alessandro Cento 2 \\ Peter Nijkamp3
}

Piet Rietveld 3

1 Università della Valle d'Aosta, Aosta, Italy; Università Bocconi, Milan, Italy;

${ }^{2}$ KLM Royal Dutch Airlines, Revenue Management Department, Milan, Italy;

${ }^{3}$ Faculty of Economics and Business Administration, VU University Amsterdam, and Tinbergen Institute. 
Tinbergen Institute is the graduate school and research institute in economics of Erasmus University Rotterdam, the University of Amsterdam and VU University Amsterdam.

More TI discussion papers can be downloaded at http://www.tinbergen.nl

Tinbergen Institute has two locations:

Tinbergen Institute Amsterdam

Gustav Mahlerplein 117

1082 MS Amsterdam

The Netherlands

Tel.: +31(0)205251600

Tinbergen Institute Rotterdam

Burg. Oudlaan 50

3062 PA Rotterdam

The Netherlands

Tel.: +31(0)10 4088900

Fax: $+31(0) 104089031$

Duisenberg school of finance is a collaboration of the Dutch financial sector and universities, with the ambition to support innovative research and offer top quality academic education in core areas of finance.

DSF research papers can be downloaded at: http://www.dsf.nl/

Duisenberg school of finance

Gustav Mahlerplein 117

1082 MS Amsterdam

The Netherlands

Tel.: +31(0)20 5258579 


\title{
Second-degree price discrimination and inter-group effects in airline routes between European cities
}

Marco ALDERIGHI, Università della Valle d'Aosta, Aosta, Italy; Università Bocconi, Milan, Italy Alessandro CENTO, KLM Royal Dutch Airlines, Revenue Management Department, Milan, Italy Peter NIJKAMP, VU University, Amsterdam, the Netherlands

Piet RIETVELD, VU University, Amsterdam, the Netherlands

\begin{abstract}
This paper presents a model of second-degree price discrimination and inter-group effects to describe the full-service pricing behaviour in the passenger aviation market. Consumer heterogeneity is assumed on both a horizontal and a vertical dimension, while various distinct market structures, some of which include low-cost carriers (LCCS), are considered. In the theoretical model framework, we derive that the rivalry between full-service carriers (FSCs) reduces fare differences between the business and leisure segments. Furthermore, the presence of LCCS increases fare gaps between leisure and business travellers, and it also induces FSCs to decrease fares in the leisure segment and eventually to increase them in the business one. This last outcome emerges from a change in passenger arrangements caused by inter-group effects. In our empirical analysis, we use data on published airfares of Lufthansa, British Airways, KLM and Alitalia for the main city-pairs from Italy to Germany, the UK and the Netherlands. Our results show that the empirical results provide support for our theoretical propositions.
\end{abstract}




\section{Introduction}

Carriers' pricing behaviour in interurban airline connections has been amply investigated in transport economics research. Among the many theoretical works describing airline pricing policies, most are based on the third-degree price discrimination approach. Borenstein and Rose (1994), for instance, describe a single-route market consisting of two segments: business and leisure travellers, each demanding flight services from one or more carriers. Since consumer segments are heterogeneous in terms of demand elasticity and brand allegiances, airlines find it profitable to price discriminate by charging full fares to less-elastic brand-sensitive business travellers and discounted fares to more-elastic less brand-sensitive leisure travellers.

This simple story, which succinctly describes the functioning of third-degree price discrimination, was often utilized to criticize the dominant view that price dispersion is positively related to market concentration. Indeed, it is possible to show that, by moving from monopoly to imperfect competition, price differentials increase in those cases where fares for brand-sensitive business travellers decrease less than those for less brand-sensitive leisure travellers (Borenstein, 1985; Holmes, 1989). This result is used as a theoretical support for a wide empirical literature which found a negative relation between price dispersion and market concentration in the airline market (Borenstein, 1985, Borenstein and Rose, 1994; Stavins, 2001; Giaume and Guillou, 2004) as well as in other service markets (Asplund et al., 2008, Borzekowski et al., 2008).

The underlying assumption behind the third-degree price discrimination argument is that the leisure and the business markets are independent, i.e. business travellers do not (or are not allowed to) buy tickets meant for leisure travellers, and vice versa. In other words, whatever the gap between leisure and business fares, carriers do not face 'passenger diversion', i.e. there is no demand switch of business travellers towards less expensive fares.

Relaxing the assumption of market independency moves the analysis toward a second-degree price discrimination approach (Stole, 2007), where the previous argument (i.e. increasing price 
differentials in more dispersed markets) continues to hold only when carriers are able to design different product qualities (e.g. 'unrestricted' vs 'restricted' fares) and price differentials remain below the business traveller quality premium (i.e. the additional value that a business traveller receives from choosing an unrestricted fare with respect to the restricted one).

The literature on revenue management abounds with examples of where passenger diversion may occur in airline markets (Botimer and Belobaba, 1999; Zhao and Zheng, 2001; Zhang and Cooper, 2005; Alderighi, 2010). This motivates our choice to abandon the simplifying assumption of market independency and to analyse airline pricing policies using the more sophisticated approach of second-degree price discrimination.

One important consequence of this choice is that, when a route is operated by a monopolist, which is forced to satisfy the quality premium constraint, the entry of a competitor cannot expand price differentials, except when there is a positive shift in quality premium. We do indeed show that, when we compare a market configuration with one (full-service) carrier with that of two (fullservice) carriers, we find that price differentials decrease or, at least, remain stable. The former occurs when the quality premium constraint ends up being slack, and the latter when it remains binding. Price dispersion, can even increase under second-degree price discrimination if we observe an expansion of the leisure market.

In our set-up, we also consider the case where the quality premium may be influenced by passenger arrangement. Business-traveller, as well as some leisure-traveller, evaluations for a flight may be affected by the participation of some passengers whose behaviour may have a negative impact (e.g. noisy travellers may reduce the ability of business travellers to work during the flight, and therefore their willingness-to-pay (WTP). If these inter-group effects play a role (Leibenstein, 1950; Becker, 1991; Katz and Spiegel, 1996), a market structure which induces a sorting of noisy travellers may increase the quality premium of business travellers. In particular, the co-existence of full-service carriers (FSCs) and low-cost carriers (LCCS) may favour a change in passenger arrangement, since LCCs, by charging low fares, can attract those passengers who are not interested 
in comfort and are mostly motivated by low prices. A more 'selected' arrangement of FSC passengers can, therefore, expand the quality premium and raise price differentials. Eventually, it can increase fares in the business segment. ${ }^{1}$ Therefore, this set-up does not exclude that price differentials may increase, but it limits this possibility to a case in which there is a carrier asymmetry.

Our modelling choice is based on the recent literature on second-degree price discrimination in oligopolistic markets. A general set-up is provided by Rochet and Stole (2002) and Armstrong and Vickers (2001) and further analysed by Dessein (2003) and Ellison (2005). ${ }^{2}$ Here, the authors allow for both horizontal and vertical differentiation between firms, endogenous quality choice, and partial coverage of the weak segment. A main conclusion is that the standard result of 'quality distortion at the bottom' (Mussa and Rosen, 1978) disappears and efficient quality allocation is usually provided. ${ }^{3}$ A similar outcome has been obtained by Alderighi (2008), when considering competition among asymmetric players. These results also lead to a re-evolution of some of the previous analyses based on exogenous quality provision (Moorthy, 1984; Katz, 1984). We take this short cut in our set-up because the previous literature shows that exogenous quality choice is not a severe limit.

This paper is also related to the work of Liu and Serfes (2006) and Hernandez and Wiggins (2009), who provide a model of second-degree price discrimination, under the assumption that the quality premium constraint remains binding in all market structures, and competition intensity is measured by the transport cost parameter (Villas-Boas and Schmidt-Mohr, 1999). Their main

\footnotetext{
${ }^{1}$ Other theoretical works find that market dispersion has a price enhancing effect (Blattberg and Wisniewski, 1989; Perloff et al., 1996; Ward et al. 2002; Goolsbee and Syverson, 2004; Chen and Riordan 2006; Alderighi, 2009). None of these, however, combines the inter-group effects with a multi-output pricing firm.

${ }^{2}$ A comprehensive review of the early works in the field is provided by Armstrong (2005).

${ }^{3}$ At least, when the participation of some consumers belonging to the lower segment is guaranteed. In fact, Yang and Ye (2008) show that, if there are some segments that remain totally unserved, the number of players increases, and quality distortion exibits a non-monotonic pattern.
} 
findings are that the business to leisure price ratio decreases with competition, and there is a $\mathrm{U}$ shaped relation between concentration and price dispersion. Finally, Justin and Myatt (2003), using a model of quality competition, showed that competition from newcomers usually occurs in the lower segments, with the consequence of pruning or reducing the incumbent participation in that segment. A similar situation emerges in our set-up when considering low-cost entry.

In the second part of the paper we will test some of the theoretical outcomes in order to verify their correspondence to the factual situation. In the empirical part, we will use half-yearly data on the airfares of Lufthansa, British Airways, Alitalia and KLM for the top 41 city-pairs from Italy to Europe (April 2001-July 2003). Contrary to what is done in most of the literature, we do not consider average prices, but perform an analysis on the basis of eight different fare classes identified by using a class map procedure.

Our empirical findings provide support to the theoretical set-up. First, it emerges that the entry of LCCs consistently reduces the fares charged. This result is in line with previous works in the field (Bennett and Craun, 1993; Whinston and Collins, 1993; Morrison and Winston, 1995; Windle and Dresner, 1995; Goolsbee and Syverson, 2008). Moreover, we find that the rivalry between (FSCs) reduces fare differences between the business and the leisure segments. This is in line, for instance, with the findings of Evans et al. (1993) and Gerardi and Shapiro (2009). Finally, the presence of LCCs induces FSCs to decrease fares in the leisure segment and to maintain and possibly increase them in the business one, implying that the gap in price between leisure and business tickets increases. A similar effect has been noted in the retail industry, where top-premium national brands have increased their prices after the introduction of store brands (Ward et al., 2002; Pauwels and Srinivasan, 2004) and in the fast food industry where the appearance of a closer competitor may slightly increase prices (Thomadsen, 2005).

The rest of the paper is organized as follows. Section 2 presents the theoretical model. Section 3 provides a description of the data, the estimation procedure, and the main results. Section 4 concludes. Details of the proofs are presented in the Appendix. 


\section{The Explanatory Model}

The model we are going to present can, in principle, be applied to all contexts where firms charge prices following a second-degree price discrimination strategy. However, we have chosen to position our discussion in the airline market context.

\subsection{Design of the model}

We analyse a market where consumers are both horizontally and vertically heterogeneous and incur interpersonal externalities. Vertical heterogeneity captures the different evaluation for quality and is related to travel motivations. In general, business travellers have a more rigid demand and, therefore, higher WTP for high quality products (e.g. unrestricted ticket) than leisure travellers. We refer to the business segment as the strong market (labelled 2), and to the leisure segment as the weak market (labelled 1). The WTP for quality of travellers belonging to the strong market and the weak market is, respectively, $t_{2}$ and $t_{1}$, with $t_{2}>t_{1}$, i.e. both types of consumers appreciate quality, although the consumers belonging to the strong market are more interested in quality than the others.

Horizontal heterogeneity is summarized by the location of consumers on a circumference of unitary length, on which, it is supposed, "products", i.e. flights, are also located. This approach is particularly appealing for the airline sector as different points on the circumference can represent travellers' ideal departure time, or the ideal locations of the origin and destination airports (in addition to the usual brand preference argument). Travellers who choose a flight which does not fully correspond to their ideal choice are subject to a constant unit transport cost $\sigma$. Since business travellers are less flexible that leisure travellers, we set the unit transport cost of business travellers $\sigma_{2}$ larger than that of leisure travellers $\sigma_{1}$, i.e.: $\sigma_{2}>\sigma_{1}$.

Interpersonal externalities come from a set of reasons, such as status signalling, preferential attachment, and group behaviour. In particular, it is supposed that the quality of a flight is affected 
by the composition of passengers and by carrier reputation. We assume that business travellers, as well as a certain proportion $\alpha \in(0,1)$ of leisure travellers, evaluate positively having comfortable and quiet seats on the flight, and the proportion $1-\alpha$ of leisure travellers do not, simply because these are those from whom such environmental externality originate. Similar to Corneo and Jeanne (1999), we model the inter-group externalities of consumers of type $i$ for the flight $j$ as:

$$
e_{i j}\left(n_{1}, n_{0}\right)=\left\{\begin{array}{cc}
\beta\left(n_{1}-n_{0}\right)-\delta_{i j} & \text { for comfort-oriented travellers } \\
0 & \text { for others }
\end{array}\right.
$$

where $n_{1}$ and $n_{0}$ are, respectively, the proportion of leisure travellers who evaluate positively being quiet (type $t_{11}$ ) on the flight and the proportion who do not (type $t_{10}$ ); $\beta>0$ is a measure of the intensity of inter-group externalities; and $\delta_{i j} \geq 0$ captures the preferential attachment, i.e. the psychological cost sustained by passenger when they fly on an LCC. It is, therefore, zero when passengers choose to fly with an $\mathrm{FSC}$, and is equal to $\delta_{2}, \delta_{1}>0$ and $\delta_{0}=0$, when passengers choose to fly with an LCC and are of type $t_{2}$ or $t_{11}$ and $t_{10}$, respectively.

We assume that both groups of travellers are uniformly distributed around the circumference, and have $0-1$ demand, and we normalize consumer mass to 1 ; the size of the weak market is $\mu_{1}=\mu \in(0,1)$, and the size of the strong market is $\mu_{2}=1-\mu ; \alpha$ is set equal to $\frac{1}{2}$ for computational reasons ${ }^{4}$. The utility that a traveller $i$ located at $x$ who purchases a flight of quality $q_{l}$ from firm $j$ located in $y_{j}$ at the price $p_{j l}$ is given by:

$$
\left(t_{i}+e_{i j}\right) q_{l}-\sigma_{i} D\left(x, y_{j}\right)-p_{j l}
$$

where $e_{i j}$ is the inter-group externality of being in flight $j, D\left(x, y_{j}\right)$ is the shortest time distance on the circumference from the location of the consumer $x$ to that of firm $j$. Travellers will choose the product that provides the maximum utility. The net utility of the outside option is normalized to zero. Note that we are, thus, modelling a situation where heterogeneous consumers are free to choose among different qualities and suppliers.

\footnotetext{
${ }^{4}$ This implies that, when identically located consumers patronize the same carrier, $n_{1}-n_{0}=0$.
} 
There are two types of firms on the market, FSCs (namely, $F$ ) and LCCs (namely, $L$ ). They differ with regard to two aspects. FSCs can offer products of different qualities: a premium product $q_{2}$ and a standard product $q_{1}$ (e.g. unrestricted and restricted tickets), while LCCs can only offer a standard product $q_{1}$ (e.g. restricted tickets). ${ }^{5}$ Moreover, LCCs have a cost advantage in production. Let $c_{j l}$ be the unit cost of firm $j$ for a product of quality $l$; therefore, we have: $c_{F 2}>c_{F 1} \geq c_{L 1}{ }^{6}$ In other words, traditional firms can offer a full range of products but at higher cost, while low-cost firms can offer a restricted range of products but at lower cost. To simplify the notation, let $c_{l}=c_{F l}, \quad c_{0}=$ $c_{L 1}$, and $u_{i l}=\left(t_{i}+e_{i l}\right) q_{l}$, for $i, l=1,2$. Note that $u_{i 2}>u_{i 1}$ for $i=1,2$, and $u_{22}-u_{21}>u_{12}-$ $u_{11}$. This last inequality is known in the literature as the single crossing property (Mirrlees, 1971).

We also assume that carriers are not able to explicitly segment consumers on the basis of passenger location on the circumference nor on the basis of passenger WTP. Implicit segmentation (i.e. which allows carriers to sort consumers by inducing self-selection) is viable only on the vertical dimension, because the single crossing property does not hold on the horizontal one. Since there are two product qualities, and two segments, the traditional strategy for FSCs is to offer the product of lower quality $q_{1}$ to the weak market, and the product of higher quality $q_{2}>q_{1}$ to the strong market. Carriers, to avoid diversion, i.e. that a $t_{2}$-type consumer will buy a product designed for $t_{1}$-type consumers, must choose $p_{F 1}$ and $p_{F 2}$, such that the net utility that a $t_{2}$-type consumer receives when she buys a product of quality $q_{2}$, is at least equal to her net utility when she buys a product of quality $q_{1}$. This means in formal terms: $u_{22}-p_{F 2} \geq u_{21}-p_{F 1}$. This inequality may also be written as:

\footnotetext{
${ }^{5}$ The FSC offer includes a wide range of characteristics, e.g. in-flight entertainment, fast check-in, waiting lounges, ground services, which further help to differentiate the product.

${ }^{6}$ The cost differences between FSCS and LCCS are amply documented. The advantages of low-cost carriers are mainly due to their organization (Franke, 2004). On the other hand, the cost difference between business tickets and leisure tickets is usually explained by differences in the quality of service and by the higher implicit cost of business seats caused by differences in the load factors (Dana, 1999; Escobari and Gan, 2007).
} 


$$
p_{F 2}-p_{F 1} \leq r,
$$

where $r=u_{22}-u_{21}$ is the quality premium of travellers belonging to the strong market. This condition is known as the incentive compatibility constraint (ICC) for the strong market. ${ }^{7}$

The simultaneous presence of different firms on the market expands the traveller's choices and makes firm's decisions more complex. We refer to a case where fares are such that, if a consumer decides to fly, she definitely purchases from the closest firms and chooses the fare designed for her type, i.e. all FSCs price schedules satisfy the ICC for the strong and the weak markets, and that fares are such that undercutting does not occur (we are excluding supercompetitive market outcomes, see: Salop, 1979). According to the utility function presented in (2), a consumer of type $t_{i}$ purchases one unit of product from the firm providing the highest utility. Consider the arc on the circumference between firm $j$ and firm $k .{ }^{8}$ The consumer $\hat{x}_{i}$ who is indifferent between purchasing from the two firms is given by:

$$
\left(t_{i}+e_{i j}\right) q_{l}-\sigma_{i} D\left(\hat{x}_{i}, y_{j}\right)-p_{j l}=\left(t_{i}+e_{i k}\right) q_{l}-\sigma_{i} D\left(\hat{x}_{i}, y_{k}\right)-p_{k l}
$$

A traveller of type $t_{i}$ belonging to the arc of circumference $j k$ located in $x_{i}$ will patronize firm $j$ if $D\left(x_{i}, y_{j}\right)<D\left(\hat{x}_{i}, y_{j}\right)$, and firm $k$ otherwise. Semi-market demand for firm $j$ by consumers of type $t$ is therefore given by: $n_{i} D\left(\hat{x}_{i}, y_{j}\right)$, where $n_{i}$ is the number of consumers of type $t_{i}$ on the market, and where $i=2$ (i.e business travellers), 11 (i.e. leisure travellers evaluating positively being quiet

\footnotetext{
${ }^{7}$ Analogously, a carrier when designing a product for the weak market has to consider how to induce leisure travellers to buy the product designed for them. The incentive compatibility constraint is said to be binding when a firm chooses the prices of high quality and of low quality products in such a way that high WTP consumers are indifferent between buying a high quality product at a high price and buying a low quality product at a low price. On the contrary, the incentive compatibility constraint is said to be slack when prices are set in such a way that consumers of the strong (weak) market will strictly prefer a high (lower) quality product to a low (high) quality product. Throughout the paper, we will only discuss the ICC for the strong market since the ICC for the weak market is always slack.

${ }^{8}$ When there are two firms we have to define arcs by considering, for instance, counter-clock wise directions.
} 
on the flight) or 10 (the other leisure travellers). Previous analysis also accommodates the monopoly case by assuming a fictitious firm providing the reservation utility zero at each point on the circumference.

In the next sub-sections we will analyse four main market structures depending on whether there are one or two FSCs and one or no LCCs (see Figure 1):

1. Monopoly: one FSC $F$ on the market, located on the circumference at $y_{F}=0$;

2. Symmetric duopoly: two FSCs on the market: namely, $F_{A}$ and $F_{B}$, equidistantly located on the circumference, respectively, at $y_{A}=0$ and $y_{B}=\frac{1}{2}$;

3. Asymmetric duopoly: one FSC $F$ and one LCC $L$ equidistantly located, respectively, at $y_{F}=0$ and $y_{L}=\frac{1}{2}$

4. Asymmetric oligopoly: two FSCs $F_{A}$ and $F_{B}$, equidistantly located, respectively, at $y_{A}=0$ and $y_{B}=\frac{1}{2}$, and one LCC $L$ in between, located at $y_{L}=\frac{1}{4}$;

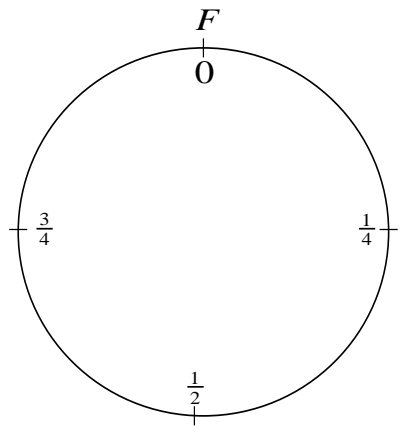

Monopoly

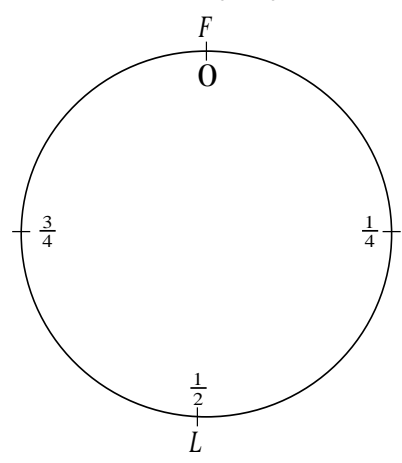

Asymmetric Duopoly

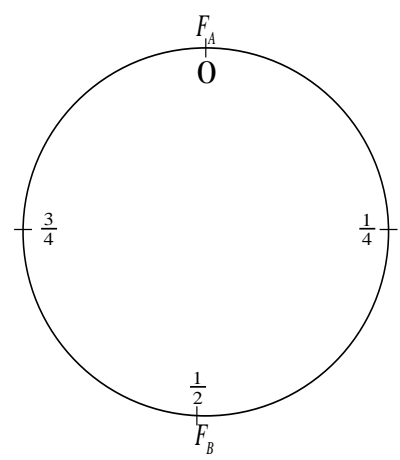

Symmetric Duopoly

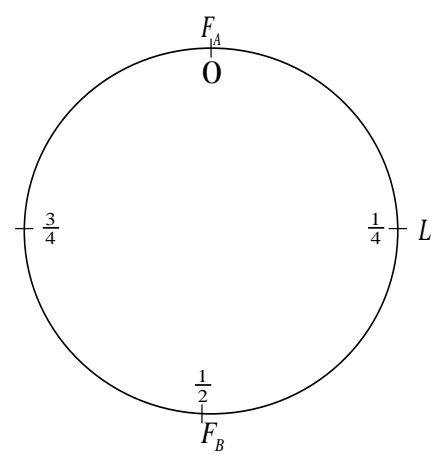

Asymmetric Oligopoly

Figure 1. Presentation of Various Market Structures 


\subsection{Monopoly Analysis}

The Previous literature suggests that monopoly analysis in the case of both horizontal and vertical differentiation produces a large set of cases depending on whether the incentive compatibility constraint (ICC) is slack or binding, and on the different coverage of the weak and the strong markets (see Desai, 2001; Alderighi, 2007; Yang and Ye, 2008). In order to simplify the analysis (and to provide more stringent predictions), we consider the case that, from our viewpoint, is the most relevant for the airline market. We therefore study the pricing behaviour in monopoly markets when, in equilibrium, the quality premium constraint is effective (the ICC is binding), and the monopolist serves all business travellers (full coverage of the business market) and some of the leisure travellers (partial coverage of the weak market). The assumption concerning a binding quality premium can be explained by the diversion argument: if a carrier tries to increase its fares in the business segment above a certain level, some business travellers will decide to buy a less attractive but much cheaper ticket. This risk is much more concrete in the monopoly, case as the lack of rivalry with other carriers does not reduce its fares. Empirical analysis also motivates our hypothesis on market coverage. It is observed that traffic usually increases by moving from monopoly to more competitive environments, and that, since business demand is quite rigid, most of the increases are usually caused by leisure passengers. These effects are, for instance, clearly documented on those routes where LCCs enter the market, e.g. the 'Southwest effect' (Morrison, 2001). In mathematical terms, this situation is obtained under the following assumptions (derived in the Appendix):

$$
\begin{aligned}
& u_{22}-c_{2} \geq \sigma_{2} \text { (full coverage of the strong market) } \\
& M \sigma_{1}<u_{11}-c_{1}<(M+1) \sigma_{1} \quad \text { (partial coverage of the weak market) } \\
& u_{11}-c_{1} \leq 2\left(u_{21}-c_{1}\right)-\sigma_{2}, \quad \text { (binding ICC), }
\end{aligned}
$$

where $M=(1-\mu) /(2 \mu)$. 
We are therefore considering a case in which the utility that business travellers receive (net of production costs) is sufficiently high; the utility that leisure travellers receive (net of production costs) is small; and business travellers have some interest in the tickets of leisure travellers. Under Assumptions (5)-(7), the profit-maximizing behaviour of the monopolist is:

$$
\max 2 \mu\left(u_{11}-p_{F 1}\right) \sigma_{1}^{-1}\left(p_{F 1}-c_{1}\right)+(1-\mu)\left(p_{F 1}+r-c_{2}\right)
$$

The first-order condition implies that:

$$
p_{F 1}=\frac{1}{2}\left(u_{11}+c_{1}+M \sigma_{1}\right) \quad \text { and } \quad p_{F 2}=p_{F 1}+r .
$$

Due to the quadratic form of the profit function, second order conditions are satisfied. Let $p_{m}=$ $p_{F 1}$, for future reference.

Note that, as a result of our modelling choice, the existence of inter-group effects does not affect the pricing decision nor the carrier profitability. In fact, the carrier cannot profitably sort travellers belonging to the weak market into two sub-segments: by raising the price in the weak market, the carrier obtains a simultaneous reduction of the number of potential travellers who want to fly in each sub-market, and therefore the inter-group effects are null, i.e. from (1), when both sub-segments participate, then $n_{1}=n_{0}$, and therefore: $e_{i j}\left(n_{1}, n_{0}\right)=0$. In order to obtain positive inter-group effects in the monopoly case, an FSC should increase the fare charged in the weak market in such a way as to fully exclude the participation of $t_{10}$-type consumers $\left(p_{E} \geq t_{1} q_{1}\right)$. In that case, the carrier is able to guarantee a participation type $t_{11}$ only if inter-group externalities are strong. We exclude this scenario from our analysis by assuming:

$$
\sigma_{1}-2 \beta q_{1}>0
$$

The following proposition summarizes the results presented in this sub-section.

Proposition 1. Assume that inter-group externalities are described by (1) and that assumptions (5)(7) and (10) hold, then: 
a) in equilibrium, the monopolist fully covers the strong market, partially covers the weak market, and ICC is binding;

b) equilibrium prices are described by (9).

We will now compare the results derived in this sub-section with those derived in the following subsections.

\subsection{Symmetric duopoly analysis}

In the symmetric duopoly case, we restrict our analysis to situations where both markets are covered. We consider two cases, depending on whether the ICC is binding or not. When the ICC is not binding, markets are separate, and the Vickrey (1964)-Salop (1979) outcome emerges in both segments (Rochet and Stole, 2002):

$$
p_{F i}=c_{i}+\frac{1}{2} \sigma_{i}, \quad i=1,2
$$

Note that, by moving from a monopolistic situation to a more competitive one, pricing strategies vary from those based on WTP to those based on the ability of firms to differentiate their products. ${ }^{9}$

From (2) and (11), full coverage of the weak market occurs when: $u_{11}-c_{1}>\frac{3}{4} \sigma_{1}$. Therefore, for any $M$ and $\sigma_{1}$, there is a parameter set for which we have simultaneously full-coverage of the weak market in the duopoly case and partial coverage in the monopoly case:

$$
\max \left\{M \sigma_{1}, \frac{3}{4} \sigma_{1}\right\}<u_{11}-c_{1}<(M+1) \sigma_{1}
$$

The results are not particularly affected by assumption (12) that is mainly motivated by the need to reduce the number of possible cases to be analysed. Using (3), we find that the ICC is slack when

\footnotetext{
${ }^{9}$ With a similar argument to that of the monopoly case, inter-group externalities do not play a role in the case of symmetric duopoly.
} 
cost differences (i.e. transport costs and production costs) are smaller than the quality premium, i.e. $\Delta=c_{2}-c_{1}+\left(\sigma_{2}-\sigma_{1}\right) / 2<r$. Let $p_{d}=p_{F 1}$ and $p_{d}+\Delta=p_{F 2}$. The second case, when the ICC is also binding in duopoly $(\Delta>r)$, is more widely analysed in the Appendix, where we show that the equilibrium prices are the result of a mixture of the transport and production costs of both segments:

$$
p_{F 1}=\left(\left(\frac{1}{2}+M\right) \sigma_{1} \sigma_{2}+2 M \sigma_{1}\left(c_{2}-r\right)+\sigma_{2} c_{1}\right)\left(2 M \sigma_{1}+\sigma_{2}\right)^{-1} \text { and } p_{F 2}=p_{F 1}+r \text {. }
$$

Note that, by moving from monopoly to duopoly, we expect that price differentials decrease or, at least, remain stable. The former implies that, in the duopoly case, the ICC is slack, while the latter that the ICC remains binding. Contrary to the third-degree price discrimination approach, this result emerges irrespective of the fact that the business demand is more rigid than the leisure demand.

In order to link this set-up with the recent literature on price dispersion, it is useful to analyse percentage price differentials in monopoly and duopoly. Using (9) and (11), it is simple to prove that if the monopoly-to-duopoly price ratio in the weak market $p_{m} / p_{d}$ is lower (higher) than $r / \Delta$, then percentage price differentials are larger (smaller) in monopoly than in duopoly. Moreover, when the ICC is binding $(\Delta>r)$, the model predicts a positive shift in percentage price differences, while, when the ICC is slack $(\Delta<r)$, both situations can be accommodated. In the second case, since $\Delta$ is positively affected by $\sigma_{2}-\sigma_{1}$, our outcome is in line with the argument put forward by Holmes (1989) and Borenstein (1985): the larger the difference in the brand strength between passengers belonging to the strong and the weak markets, the more likely the (percentage) price differentials are increasing.

Predictions concerning a higher or lower price dispersion caused by a change in the market structure may also be accommodated by the model. We use as a measure of price dispersion the coefficient of variation, i.e. $\quad C V=\left(n_{1}\left(p_{1}-\bar{p}\right)+n_{2}\left(p_{2}-\bar{p}\right)\right)^{1 / 2} / \bar{p}, \quad$ where 
$\bar{p}=\left(n_{1} p_{1}+n_{2} p_{2}\right) /\left(n_{1}+n_{2}\right)$; and where $n_{1}$ and $n_{2}$ are, respectively, the total number of passengers of the leisure and business segment. ${ }^{10}$ Simple computations imply that:

$$
C V_{d}=\frac{\Delta \sqrt{\mu(1-\mu)}}{\mu p_{d}+(1-\mu)\left(p_{d}+\Delta\right)^{\prime}} \quad C V_{m}=\frac{r \sqrt{M S_{1} \mu(1-\mu) /\left(M S_{1} \mu+(1-\mu)\right)}}{M S_{1} \mu p_{m}+(1-\mu)\left(p_{m}+r\right)}
$$

The comparison of the two expressions is not straightforward. ${ }^{11}$ Different parameter values push in different directions. As in the previous case, a remarkable role is played by the monopoly-to-duopoly price ratio in the weak market $p_{m} / p_{d}$, and by the quality premium to cost difference ratio $r / \Delta$. In addition to this, since in the monopoly equilibrium the weak market is only partially covered, traveller composition plays an additional role. In particular, the characteristics of the $C V$ imply that, for a given $p_{m} / p_{d}$ and $r / \Delta$, price dispersion is more likely to increase in those market configurations where the size number of business and leisure travellers is more similar. This prediction is consistent with the findings in Gerardi and Shapiro (2009) where price dispersion in 'big-city routes' characterized by both business and leisure travellers is higher than in 'leisure cities routes'.

The following proposition summarizes the above analysis.

Proposition 2. Assume that inter-group externalities are described by (1) and that assumptions (5)-

(7), (12) hold, then:

a) markets are fully covered;

b) equilibrium prices are described by (12) when $\Delta<r$ and by (13) when $\Delta>r$;

c) when $\Delta<r$, the ICC is not binding (i.e. price differences moving from the monopoly to the duopoly case decrease) and, when $\Delta>r$, the ICC is binding,

\footnotetext{
${ }^{10}$ The coefficient of variation is the ratio of the standard deviation to the mean. When considering only two fare levels, the coefficient of variation is double the Gini coefficient.

${ }^{11}$ Simulations confirm that the results are consistent with the informal treatment that we are going to present.
} 
d) moving from monopoly to symmetric duopoly, percentage price differences decrease when $p_{m} / p_{d}<r / \Delta$, and increase when $p_{m} / p_{d}>r / \Delta ;$ and

e) if percentage price differences decrease then the ICC is slack.

Some of these implications are tested in the empirical part (Table 4).

\subsection{Asymmetric duopoly analysis}

In this section, we focus on the entry of an LCC in a monopolistic market. Contrary to the previous cases, we show that inter-group externalities affect the equilibrium outcome. In particular, we will show how these effects increase full-service price differentials, and that they can eventually induce a rise in the FSC's fares in the strong market. Intuitively, the presence of an LCC induces a different allocation of the two sub-segments of leisure travellers between the two carriers. The LCC attracts more $t_{10}$-type travellers and less $t_{11}$-type travellers. Consequently, a lower share of $t_{10}$-type travellers increases the valuation of $t_{2}$-type and $t_{11}$-type consumers for a flight operated by an FSC.

In the asymmetric duopoly case, we assume that there is an $\mathrm{FsC}$, located at 0 , and an LCC located at $1 / 2$. The low-cost carrier has a competitive advantage in costs, but it cannot provide the full range of products (i.e. it is not able to produce the quality $q_{2}$ ). As an LCC cannot provide a high quality product for type $t_{2}$, it offers the same quality for both markets, which corresponds to $q_{1}$. Depending on the level of vertical heterogeneity, the LCC may, or may not, attract business travellers. We focus on the case in which, the FSC has no competition on the strong market. ${ }^{12}$ It corresponds to a situation in which $t_{2}$ and $\delta_{2}$ are sufficiently high, i.e. it is 'too costly' for a business

\footnotetext{
${ }^{12}$ There is some empirical evidence that in the EU aviation market, LCCs target some business travellers. However, our data refer to an early stage of market liberalization, where the share of business travellers who considered flying with an LCC was quite small.
} 
traveller to choose an LCC. Consequently, business fares are only subjected to the quality premium constraint that, under similar conditions to the monopoly case, is binding.

Due to the presence of LCCs, $t_{11}$-type and $t_{10}$-type consumers located in the same place may prefer to patronize different carriers. Using equations (1) and (2), the utility a $t_{11}$-type traveller located in $x$ receives when patronizing the FSC is: $\left(t_{1}+2 \beta\left(x_{11}-x_{10}\right)\right) q_{1}-\sigma_{1} D\left(x, y_{F}\right)-p_{F 1}$, and the utility she receives when patronizing the LCC is: $\left(t_{1}-2 \beta\left(x_{11}-x_{10}\right)-\delta_{1}\right) q_{1}-\sigma_{1} D\left(x, y_{L}\right)-$ $p_{L}$, where $2 x_{11}$ and $2 x_{10}$ are, respectively, the number of $t_{11}$-type and $t_{10}$-type passengers travelling with the FSC; and $\delta_{1}$ is a measure of the preferential attachment. Note that $t_{11}$-type evaluation is affected by the composition of passengers, $2 \beta\left(x_{11}-x_{10}\right)$, and by the 'brand' evaluation $\delta_{1}$, i.e the traveller is damaged by flying in a less prestigious, or a less comfortable carrier. For $t_{10}$-type consumers, there are no inter-group externalities and, therefore, the evaluations for the FSC and LCC offers are, respectively: $t_{1} q_{1}-\sigma_{1} D\left(x, y_{F}\right)-p_{F 1}$ and $t_{1} q_{1}-\sigma_{1} D\left(x, y_{L}\right)-p_{L}$. Let $\hat{x}_{11}$ and $\hat{x}_{10}$ be the corresponding indifferent consumers for the two types. Therefore (details on the rest of the model are provided in the Appendix):

$$
\hat{x}_{11}-\hat{x}_{10}=\left(q_{1} \delta_{1}\right) /\left(2 \sigma_{1}-4 \beta q_{1}\right)>0 .
$$

Note that, since the ICC is binding, the price charged in the strong market is such that a business traveller is indifferent to buying a ticket of quality $q_{2}$ and a ticket of quality $q_{1}$, both offered by the FSC. However, since $x_{11}-x_{10}>0$, the existence of inter-group effects implies that $p_{F 2}=p_{F 1}+r_{\beta}$, where $r_{\beta}=t_{2}\left(q_{2}-q_{1}\right)+2 \beta\left(x_{11}-x_{10}\right)\left(q_{2}-q_{1}\right)$. Moreover, if the price charged by the FSC in the weak market is not too low when compared with the price charged in monopoly, the existence of inter-group effects may cause higher business fares in the asymmetric duopoly case than in the monopoly case. Solving the maximization problem of the FSCs and the LCCs, equilibrium prices are (see the Appendix):

$$
\begin{gathered}
p_{L}=\frac{1}{6}\left(3 \sigma_{1}+4 M \sigma_{1}+4 c_{0}+2 c_{1}-I\right), \\
p_{F 1}=\frac{1}{6}\left(3 \sigma_{1}+8 M \sigma_{1}+2 c_{0}+4 c_{1}+I\right) \text { and } p_{F 2}=p_{F 1}+\left(t_{2}+\beta I / \sigma_{1}\right)\left(q_{2}-q_{1}\right),
\end{gathered}
$$


where $I=\left(\delta_{1} \sigma_{1} q_{1}\right) /\left(\sigma_{1}-2 \beta q_{1}\right)$. The following proposition summarizes the main results of this sub-section.

Proposition 3. Assume that inter-group externalities are described by (1) and that assumptions (5)(7), (12) hold, then:

a) equilibrium prices are given by: (15)-(16);

b) price differentials between the business segment and the leisure segment are higher in the asymmetric duopoly case than in the monopoly case; and

c) for a sufficiently high cost differential $\left(c_{1}-c_{0}\right)$, fares are lower in the asymmetric duopoly case than in the monopoly case in the weak market but higher in the strong market.

\subsection{Asymmetric oligopoly analysis}

In this sub-section we analyse the case where there are two FSCs equidistantly located and an LCC positioned between them. This market is characterized by two relevant aspects. First, in the weak market, FSCs sustain quite strong competition, due to the proximity of the LCC, but they also benefit from inter-group externalities. Second, the strong market competition remains similar to that of the symmetric duopoly case, since competition among the FSCs eliminates (when $\delta_{2}$ is sufficiently high) both the possibility to exploit inter-group externalities and the competitive pressure of Iccs. Therefore, although the oligopoly game is complex, a simple solution can be obtained since the pricing behaviour of FSCs are separate between the weak and the strong market. In fact, equilibrium prices in the strong market are given simply by equation (11), while in the weak market, prices are obtained by the interplay of the three firms. The methodology to find the market prices in the weak market is similar to that of the asymmetric duopoly case and is reported in the Appendix. We find that:

$$
\begin{aligned}
& p_{L}=\frac{3}{10} \sigma_{1}+\frac{1}{5}\left(3 c_{0}+2 c_{1}\right)-\frac{2}{5} \frac{\delta_{1} \sigma_{1} q_{1}}{2 \sigma_{1}-3 \beta q_{1}} ; \\
& p_{F 1}=\frac{7}{20} \sigma_{1}+\frac{1}{5}\left(c_{0}+4 c_{1}\right)+\frac{1}{5} \frac{\delta_{1} \sigma_{1} q_{1}}{2 \sigma_{1}-3 \beta q_{1}} .
\end{aligned}
$$


The following proposition summarizes the main results of this section.

Proposition 4. Assume that inter-group externalities are described by (1) and that assumptions (5)-

(7), (12) hold, then:

a) prices in the strong market are not affected by the presence of an LCC and are given by (11), and equilibrium prices in the weak market are given by (17) and (18);

b) price differentials between the business segment and the leisure segment are smaller in the asymmetric oligopoly case than in the asymmetric duopoly case;

c) for a sufficiently high cost differential $\left(c_{1}-c_{0}\right)$, price differentials between the business segment and leisure segment are higher in the asymmetric oligopoly case than in the symmetric duopoly case.

\section{Empirical Analysis of European Airfares}

\subsection{Data}

Data for this analysis refer to the first years (2001-2003) after the end of the European airline deregulation process (1988-1997) which were characterized by some important changes. First, most of the national carriers were privatized or partially privatized and started adopting sophisticated pricing techniques (Talluri and van Ryzin, 2005). Second, although carriers had the freedom to adjust their network structure in accordance with their needs, network modifications were quite limited. For instance, the European routes analysed in this work maintained the same full-service operators for all the period of analysis, and the FSCs operating the routes were based in the country of one of the endpoints of the route. Third, a consistent growth of LCC was observed, even if at the end period (July 2003), in 41 selected routes, we continued to observe a market dominance of the FSCs for most of the city-pairs. 
The main source of data is posted fares retrieved from the computer reservation system Galileo for 41 city-pairs in the period April 2001 - July 2003. The fares concern operating non-stop direct flights between Italy and three European countries: UK, Germany, and the Netherlands, involving four legacy carriers, viz. Lufthansa (LH), British Airways (BA), Alitalia (AZ), and KLM(KL). The use of city-pairs is usually preferred to that of airport-pairs when the analysis also involves LCCs, as entry often occurs in secondary airports (see, e.g., Nero, 1998).

Apart from the limitation concerning the duration of the period under evaluation and the number of destinations, this data has the value of including detailed information on booking class, cabin, ticketing restrictions, etc. An in-depth analysis of fare characteristics was conducted in order to obtain the eight homogeneous fare classes reported in Table 1.

Usually, carriers label classes with capital letters. For example, the promotional classes of Alitalia are $\mathrm{O}$ and $\mathrm{N}$, while those of Lufthansa are $\mathrm{V}$ or $\mathrm{W}$. Our classification is obtained by analysing the ticket characteristics of the four FSCs for each of their classes, and assigning each original class of each carrier to one of the eight classes valid for all the carriers. The main attributes, that we have taken into account are ticket characteristics (ticket cancellation, travel date change penalties, purchase time limits, or minimum stay at the travel destination, Sunday rule, etc.) and ground services (flight fast check-in, VIP waiting lounges). ${ }^{13}$

Additional information concerning passengers, flows, frequencies, and seats offered on anbiannual basis has been collected from OAG databases and airport authorities. Information on sociodemographics on origin and destination areas has been collected from the Eurostat Euregio database.

Table 1 - Class mapping of carriers' airfares

\footnotetext{
${ }^{13}$ The choice to use a class mapping procedure to classify different fares comes from the observation that high collinearity among fare attributes (which are usually nested, moving from the lowest to the highest fare), makes their simultaneous use in the estimation difficult (Stavins, 2001).
} 


\begin{tabular}{ccccccccccc}
\hline \multicolumn{2}{c}{ TYPE OF FARE } & & & & & \multicolumn{3}{c}{ std. } \\
(8 classes) & (3 classes) & AZ & KL & BA & LH & mean & dev & min & max \\
\hline & & & & & & & & & \\
Promotional & Leisure & O-N & V-T & Q-N & W-V & 167 & 33.9 & 99 & 295 \\
Discounted 1 & Leisure & W-T & L & V-L & Q-H & 276 & 60.1 & 165 & 411 \\
Discounted 2 & Leisure & Q & K & M & M & 361 & 58.7 & 240 & 494 \\
Economy 1 & Intermediate & B & B & K-H & B & 454 & 102.3 & 300 & 732 \\
Economy 2 & Intermediate & M & S & B-I & B & 580 & 100.3 & 320 & 838 \\
Unrestricted 1 & Business & Y & Z & Y & Y & 815 & 161.0 & 440 & 1092 \\
Unrestricted 2 & Business & I & C & D & D & 887 & 151.7 & 558 & 1171 \\
Unrestricted 3 & Business & C & J & J & C & 898 & 207.5 & 574 & 1459 \\
\hline
\end{tabular}

Contrary to US data, we do not have information on ticket fares but only on posted fares. Although this is a major shortcoming for the analysis of European markets, in this specific case this is not critical since we are interested in studying the change in the fare schedule in different market structures, and not, for instance, fare dispersion (where quantities matter).

The construction of the sample begins by converting posted fares into half-yearly information. We take three different steps. First, we exclude one-way fares from the analysis. This is justified because one-way tickets are rarely sold by FSCs in the European market. Second, we have transformed the raw data on posted fares into monthly data (obtaining 14,152 different airfares), and added information on the presence or absence of LCCs on the route. Within the sample, we have 12 city-pairs with the following LCCs: Ryanair, easyJet, Basiqair, Volare Web, British Midland, Air Berlin, Virgin Express and Hapag Lloyd Express. Finally, to match the data frequency of other sources, as well as to account for pricing practices of carriers, we convert previous observations into bi-annual data, averaging information by period, route and carrier. To be consistent with OAG 
practices, the semesters are called Winter (which lasts 5 months from November to March) and Summer (which lasts 7 months from April to October). The resulting database of 1269 observations concerns 41 routes, 4 carriers, 8 fare classes for 5 periods (semesters). ${ }^{14}$

Summary statistics are presented in Table 2.

Table 2 - Descriptive statistics

\begin{tabular}{lllll}
\hline VARIABLE & MEAN & STD. & MIN & MAX \\
& \multicolumn{5}{l}{ DEV. } & \\
& & & & \\
FARE & 6.1173 & 0.5862 & 4.7767 & 7.2855 \\
LCC & 0.0784 & 0.1481 & 0.0000 & 0.6364 \\
SHARE & 0.7236 & 0.2768 & 0.1456 & 1.0000 \\
FSC & 0.5145 & 0.4999 & 0.0000 & 1.0000 \\
ENPL & 0.5117 & 0.1409 & 0.2335 & 0.8698 \\
DEN & 0.5125 & 0.3564 & 0.1638 & 1.4136 \\
\hline
\end{tabular}

\subsection{The empirical model}

Our econometric approach is based on the following specification:

$$
F A R E_{i j t c}=\alpha+\delta_{i j}+\gamma_{t}+\beta_{1} S H A R E_{i j t}+\beta_{2} L C C_{j t}+\sum_{c=1}^{8} \theta_{c} C L A S S_{c}+\varepsilon_{i j t c}
$$

\footnotetext{
${ }^{14}$ This is an unbalanced panel since some carriers on specific routes and in specific periods do not post all the class fares. In particular, some promotional fares are often not posted by Alitalia or Lufthansa, and likewise, some other economy and business fares may not be posted by KLM. This is an additional rationale to aggregate the initial 8 classes into 3 main classes.
} 
where $F A R E_{i j t c}$ is the log fare charged by carrier $i$ on route $j$ in period $t$ for a ticket class $c$; $\delta_{i j}$ is the route carrier fixed effect; $\gamma_{t}$ is the period fixed effect; $S H A R E_{i j t}$ is the passenger share of carrier $i$ on route $j$ in period $t ; C L A S S_{c}$ is dummy variable for fare class $c$; and $L C C_{j t}$ is the market share of LCCs on route $j$ in period $t$ (number of frequencies over the total).

Some extensions include the following dummy variables: $T W O_{i j t}^{L E I}$ is a dummy variable for the presence of a second FSC when the fare is intended for leisure travellers (fare classes 1, 2 and 3), and $T W O_{i j t}^{B U S}$ is a dummy variable for the presence of a second FSC when the fare is for business travellers (fare classes 6, 7 and 8).

The previous literature has emphasized the risk of endogeneity of the variables SHARE and LCC that can be potentially correlated with the error process. Standard econometric techniques suggest, therefore, that equation (19) should be estimated using instrumental variables (IV). A valid instrument for the variable SHARE, proposed by Borenstein (1989) and afterwards utilized by Borenstein and Rose (1994) and Gerardi and Shapiro (2009), is $E N P L_{i j t}$, the ratio between the geometric mean of enplanements of carriers at the two endpoints and the sum across all carriers of the geometric mean of each carrier's enplanement at the endpoints.

Endogeneity issues on the variable LCC are more serious because they concern one of the main variables of interest in our analysis. Endogeneity should derive from the fact that LCCs are attracted by most profitable markets and FSC fares are also positively related to market profitability. Therefore, if market profitability is not in the explanatory variables, the error process is positively correlated with the low-cost variable, and the estimated fare reduction due to the entry of an LCC is underestimated.

The recent literature suggests that it is difficult to find valid instruments for the entry of LCCs (see Gerardi and Shapiro, 2009). Berry (1992) suggested that the presence of an LCC on the two endpoints of a route increases the probability of entry on this route. Goolsbee and Syverson (2008) used this variable in order to capture the potential entry of an LCC, and showed that FSCs react to the threat of entry by reducing their prices some months before the entry. However, their analysis is 
quite different from ours, because they selected only those routes in which entry occurs, and therefore do not account for those routes that were less affected by LCCS entry decision. In our analysis, we cannot rely on this variable since the European market in 2001-2003 has a very different structure from the US market. In our study, since there were no bases of LCCs in Italy, this variable was always zero.

We therefore decided to provide a new instrument for the presence of an LCC: the potential demand on the route. The proposed instrument is clearly correlated with the entry decision of the LCCs (since they want to enter dense markets: see, e.g., Boguslaski et al., 2004; Sinclear, 1995), but is marginally correlated with the error process, since FSC profitability is mainly affected by some unmeasurable variable such as the industrial relations among linked areas, etc. We choose to measure the potential demand with $D E N_{i j t}$, that is, the geometric average of the population density in the regions of the two endpoints (in thousands of inhabitants per square kilometre). This variable is preferred to a measure of the population, which is more affected by the size of the region under consideration. ${ }^{15}$

\subsection{Empirical results}

Equation (19) is estimated using panel fixed effects, including a carrier-route fixed effect and a timeperiod fixed effect. Standard errors are clustered by route in order to control for autocorrelation, as well as for correlation between carriers on the same route. The results are reported in Table 3 . All

\footnotetext{
${ }^{15}$ The European geographical partition of Member States is based on the NUTS (Nomenclature of Statistical Territorial Units) classification. The size of NUTS territorial areas is quite heterogeneous, since it corresponds to the administrative division of countries which are quite different. We use the NUTS1 classification for the UK, the Netherlands and Germany, and NUTS2 for Italy.
} 
the models are estimated with the two-stage instrumental variable estimator, apart from Model 1 that presents the ordinary least square estimates. ${ }^{16}$

Models 1-2 show that the market share of $L C C s$ on a route has a negative impact on FSC fares. In order to measure the impact of the entry of an LCC, we have also estimated the model using a dummy variable for the presence of LCC. The results are quite similar, but the use of the route share of LCCs increases the significance of the coefficient. This reflects that the pricing behaviour of an FSC is more affected when there is a larger involvement of LCCs.

The coefficients of fare classes are statistically significant and have the expected ordering. We choose CLASS4 as the reference class. As expected, the coefficients of the lower classes have a negative sign, and those of higher classes a positive one. In those cases, where we split the sample by classes (Models 3-5), the reference class for the leisure segment is CLASS3, for the intermediate segment it is CLASS4, and for the business segment it is CLASS8. The coefficient of SHARE has the right sign but, in most of the estimates, is not significant (see below, for an explanation).

\footnotetext{
${ }^{16}$ The Durbin-Wu-Hausman chi-square test in some estimates rejects the assumption of exogeneity of $L C C$ and SHARE. We therefore decided to consider these variable as endogenous in line with the current literature. The qualitative results are not affected by this choice. (Estimates where one or both variables are considered exogeneous are available upon request.) Standard tests for the detection of weak instruments are applied. For Model 2, the F-statistics for excluded instruments for $L C C$ and SHARE are, respectively, 11.83 and 52.79, which are above the value suggested by Staiger and Stock (1997) for identifying weak instruments. We also test the instrument relevance comparing the Shea partial R-squared with the Bound et al. (1995) partial R-squared. Both statistics provide similar values for the two variables suggesting that the model is fully identified (in both cases, the partial R-squared is 0.19 for $L C C$ and 0.42 for $S H A R E$ ).
} 
Table 3 - Main estimations (dependent variable: $F A R E$ )

\begin{tabular}{|c|c|c|c|c|c|c|c|c|}
\hline & (1) & (2) & (3) & (4) & (5) & (6) & (7) & (8) \\
\hline \multirow[t]{2}{*}{ VARIABLES } & OLS & IV & IV & IV & IV & IV & IV & IV \\
\hline & FULL SMPL & FULL SMPL & LEISURE & INTERM. & BUSINESS & FULL SMPL & NO LCC & ONLY LCC \\
\hline \multirow[t]{2}{*}{$L C C$} & $-0.0896 * *$ & $-0.235^{* *}$ & $-0.454 * *$ & $-0.304 * *$ & $0.107^{*}$ & $-0.237 * *$ & & $-0.406 * *$ \\
\hline & $(0.0452)$ & $(0.105)$ & $(0.206)$ & (0.149) & $(0.0593)$ & $(0.105)$ & & (0.197) \\
\hline \multirow[t]{2}{*}{ SHARE } & 0.0267 & 0.0568 & -0.0485 & -0.174 & $0.0894 * * *$ & 0.0746 & -0.0141 & $0.290 * *$ \\
\hline & (0.0719) & $(0.0761)$ & $(0.140)$ & $(0.136)$ & $(0.0306)$ & $(0.0792)$ & $(0.127)$ & $(0.133)$ \\
\hline \multirow[t]{2}{*}{$T W O^{L E I}$} & & & & & & $0.0617^{*}$ & $0.119 * * *$ & 0.0563 \\
\hline & & & & & & $(0.0355)$ & $(0.0443)$ & (0.0399) \\
\hline \multirow[t]{2}{*}{$T W O^{B U S}$} & & & & & & -0.00465 & -0.0164 & -0.0671 \\
\hline & & & & & & $(0.0380)$ & $(0.0363)$ & $(0.0541)$ \\
\hline \multirow[t]{2}{*}{ CLASS1 } & $-0.992 * * *$ & $-0.994 * * *$ & $-0.755 * * *$ & & & $-1.023 * * *$ & $-0.970 * * *$ & $-1.089 * * *$ \\
\hline & $(0.0290)$ & (0.0293) & $(0.0222)$ & & & $(0.0257)$ & $(0.0337)$ & $(0.0314)$ \\
\hline \multirow[t]{2}{*}{ CLASS2 } & $-0.550 * * *$ & $-0.553 * * *$ & $-0.309 * * *$ & & & $-0.586 * * *$ & $-0.582 * * *$ & $-0.603 * * *$ \\
\hline & $(0.0155)$ & (0.0159) & $(0.0184)$ & & & $(0.0231)$ & $(0.0324)$ & $(0.0280)$ \\
\hline \multirow[t]{2}{*}{ CLASS3 } & $-0.240 * * *$ & $-0.240 * * *$ & - & & & $-0.269 * * *$ & $-0.272 * * *$ & $-0.279 * * *$ \\
\hline & (0.0179) & (0.0179) & & & & $(0.0182)$ & $(0.0273)$ & $(0.0192)$ \\
\hline \multirow[t]{2}{*}{ CLASS5 } & $0.274 * * *$ & $0.271 * * *$ & & $0.284 * * *$ & & $0.271 * * *$ & $0.267 * * *$ & $0.275 * * *$ \\
\hline & (0.0117) & $(0.0120)$ & & $(0.0112)$ & & (0.0117) & $(0.0180)$ & $(0.0141)$ \\
\hline \multirow[t]{2}{*}{ CLASS6 } & $0.563 * * *$ & $0.560 * * *$ & & & - & $0.565^{* * *}$ & $0.494^{* * *}$ & $0.649 * * *$ \\
\hline & $(0.0277)$ & $(0.0280)$ & & & & (0.0405) & $(0.0497)$ & $(0.0533)$ \\
\hline \multirow[t]{2}{*}{ CLASS7 } & $0.676 * * *$ & $0.672 * * *$ & & & $0.119 * * *$ & $0.679 * * *$ & $0.612 * * *$ & $0.752 * * *$ \\
\hline & $(0.0272)$ & $(0.0274)$ & & & $(0.00984)$ & $(0.0390)$ & $(0.0426)$ & (0.0518) \\
\hline \multirow[t]{2}{*}{ CLASS8 } & $0.691 * * *$ & $0.691 * * *$ & & & $0.247^{* * *}$ & $0.695 * * *$ & $0.649 * * *$ & $0.801 * * *$ \\
\hline & $(0.0249)$ & $(0.0250)$ & & & $(0.0211)$ & $(0.0317)$ & $(0.0320)$ & $(0.0663)$ \\
\hline Observations & 1269 & 1269 & 497 & 375 & 397 & 1269 & 585 & 684 \\
\hline R-squared & 0.960 & 0.960 & 0.919 & 0.798 & 0.824 & 0.961 & 0.966 & 0.966 \\
\hline
\end{tabular}

Note: Table 3 only reports the coefficients and thestandard errors of the variables of interest. The dependent variable is the log of the quoted fare of a

return ticket sold in Italy (FARE). All models include carrier-route specific fixed effects and period fixed effects. Robust standard errors are clustered by route and are reported in parentheses. $* * *, * *$, and $*$ denote significance at the $1 \%, 5 \%$, and $10 \%$ levels, respectively. 
The theoretical analysis provides two main arguments concerning the price behaviour of FSCs. One point is that the entry of LCCs reduces fares in the weak market and possibly increases them in the strong one. The other is that fare differentials (between the strong and the weak market) will decrease (or at least remain unchanged) when one moves from one to two FSCs. In Table 4 we summarize the main testable predictions of the theoretical model and the corresponding empirical outcomes.

Models 3-5 analyse the impact of the entry of LCCs on the fare structure. ${ }^{17}$ We observe a clear pattern indicating a negative and statistically significant impact of $L C C$ on fares in the leisure segment and in the intermediate segment, and a positive and statistically significant increase for the business segment. This confirms the theoretical result that this outcome is likely to emerge if there is a sufficient cost difference between LCCs and FSCs and inter-group externalities are at work.

Quite interestingly, we also find that SHARE has a negative sign for the leisure and the intermediate classes (even if it is not significant), and a positive and highly significant value for the business class. The rationale behind this result is that higher market shares (and therefore higher frequencies and higher quality of the product offered) allow carriers to charge higher fares in the business segment; however, it also induces the FSCs to play more aggressively on the leisure segment in order to attract a large number of leisure passengers to fill the excessi capacity. These opposite effects may be the reason for the low significance of SHARE when we use a single variable for all classes.

Models 6-8 can be used to investigate the relationship between class prices and market structure. Since our database does not include cases where the number of FSCs change on the same route, the empirical analysis cannot address the question whether fares reduce or increase by moving from a case with one FSC to another with two FSCs. However, our data are useful in

\footnotetext{
${ }^{17}$ The leisure category consists of classes 1-3 (class 3 is the reference case); the intermediate category consists of classes 4 and 5 ( 5 is the reference case); The business category consists of classes 6,7 and 8 ( 6 is the reference case).
} 
capturing price differentials. Variables $T W O^{L E I}$ and $T W O^{B U S}$ are employed for this goal. Equations (20) and (21) describe FSC fares in the leisure and, the business segments when there are one or two FSCs:

$$
\begin{array}{ll}
F A R E_{O N E}^{L E I}=X_{O N E}+C L A S S^{L E I}, & F A R E_{T W O}^{L E I}=X_{T W O}+C L A S S^{L E I}+T W O^{L E I}, \\
F A R E_{O N E}^{B U S}=X_{O N E}+C L A S S^{B U S}, & F A R E_{T W O}^{B U S}=X_{T W O}+C L A S S^{B U S}+T W O^{B U S},
\end{array}
$$

where $X_{O N E}$ and $X_{T W O}$ summarize all the variables of (19) that are not present in (20) and (21), when there are, respectively, one or two FSCs. Then, it follows that:

$$
\begin{aligned}
& \triangle F A R E^{L E I}=F A R E_{T W O}^{L E I}-F A R E_{O N E}^{L E I}=\left(X_{T W O}-X_{O N E}\right)+T W O^{L E I}, \\
& \Delta F A R E^{B U S}=F A R E_{T W O}^{B U S}-F A R E_{O N E}^{B U S}=\left(X_{T W O}-X_{O N E}\right)+T W O^{B U S} .
\end{aligned}
$$

Therefore, fare differentials are: $\triangle F A R E^{L E I}-\triangle F A R E^{B U S}=T W O^{L E I}-T W O^{B U S}$ that can also be interpreted as $\left(F A R E_{O N E}^{B U S}-F A R E_{O N E}^{L E I}\right)-\left(F A R E_{T W O}^{B U S}-F A R E_{T W O}^{L E I}\right)$, i.e. the difference between the fare gap when there is only one FSC and when there are two FSCs. Table 4 shows that this gap is positive and statistically significant for Models 7 and 8 , in line with the theoretical outcome. Therefore, we find that fare gaps reduce when moving towards more competitive environments, and that the ICC is likely to be slack in non-monopolistic markets. 


\begin{tabular}{|c|c|c|c|c|}
\hline PROPOSITION(S) & MODEL PREDICTIONS & TEST & $p$-value & MODEL \\
\hline 3,4 & Low-cost entry decreases full-service fares in the weak market & $L C C^{L E I}<0$ & $0.014^{* *}$ & Model 3 \\
\hline 3,4 & Low-cost entry increases full-service fares in the strong market & $L C C^{B U S}>0$ & $0.036 * *$ & Model 5 \\
\hline 3,4 & Low-cost entry increases fare differentials & $L C C^{L E I}<L C C^{B U S}$ & $0.000 * * *$ & Models 3-5 \\
\hline 2,4 & Fare differences moving from one to two FSCs decrease (full sample) & $T W O^{L E I}>T W O^{B U S}$ & 0.135 & Model 6 \\
\hline 2 & Fare differences moving from one to two FSCs decrease (with no low-cost) & $T W O^{L E I}>T W O^{B U S}$ & $0.015^{* *}$ & Model 7 \\
\hline 4 & Fare differences moving from one to two FSCs decrease (with low-cost) & $T W O^{L E I}>T W O^{B U S}$ & $0.036 * *$ & Model 8 \\
\hline \multicolumn{5}{|c|}{ OTHER RELEVANT RESULTS } \\
\hline & Market shares positively affects high fares, but & $M S_{b u s}>0$ & $0.002 * * *$ & Model 5 \\
\hline & have no significant result on fares in other classes & $M S_{l e i}=0$ & 0.728 & Model 3 \\
\hline & & $M S_{\text {int }}=0$ & 0.202 & Model 4 \\
\hline
\end{tabular}




\section{Conclusions}

In this paper we have investigated the pricing behaviour of FSCs by generalizing a simple view of the functioning of the market proposed by Borenstein and Rose (2004). We have relaxed the assumption of market independency, and we have accounted for inter-group effects. The empirical evidence concerning the European market provides some support for our conclusions. When the market structure moves from monopoly to duopoly, the price gap reduces suggesting that the quality premium constraint becomes slack. Therefore, in competitive environments, third-degree and second-degree price discrimination approaches give the same results. Nevertheless, the latter provides more stringent conclusions on the effects of the 'peer' competition in the market. This also helps to enrich the debate concerning market structure and price dispersion. Moreover, we have shown how inter-group effects may have some impact on pricing behaviour in the second-degree price discrimination approach through relaxing the quality premium constraint and allowing the FSCs to charge larger price differentials between restricted and unrestricted fares. This aspect is too often neglected in the analysis of markets and could be the subject of future research.

\section{References}

Alderighi, M., 2007. Non-linear pricing in asymmetric duopoly, Australian Economic Papers 46, 205-22.

Alderighi, M., 2009. Competition (sorting effect) may favour a monopolist, Journal of Economics 98, 2009, 247-255.

Alderighi, M., 2010. The role of fences in oligopolistic airline markets, Journal of Transport Economics and Policy, forthcoming.

Armstrong, M. and Vickers, J. 2001. Competitive Price Discrimination, RAND Journal of Economics 32, 579605.

Asplund, M., Eriksson, R., Strand, N., 2008. Price discrimination in oligopoly: evidence from regional newspapers, Journal of Industrial Economics 56(2), 333-346. 
Becker, G.S., 1991. A note on restaurant pricing and other examples of social influences on price, Journal of Political Economy 99, 1109-1116.

Bennett, R.D., Craun, J.M., 1993. The airline deregulation evolution continues: the Southwest effect. US Department of Transportation, Washington, DC (mimeo).

Blattberg, R., Wisniewski, K., 1989. Price-induced patterns of competition, Marketing Science 8, 291-30.

Boguslaski, C., Ito, H., Lee, D., 2004. Entry patterns in the Southwest airlines rote system, Review of Industrial Organization 25, 317-350.

Borenstein, S., 1985. Price discrimination in free-entry markets, RAND Journal of Economics 16(3), 380-97.

Borenstein, S., Rose, N.L., 1994. Competition and price dispersion in the U.S. airline industry, Journal of Political Economy 102(4), 653-683.

Borzekowski, R., Thomadsen, R., Taragin, C., 2008. Competition and price discrimination in the market for mailing lists, Quantitative Marketing and Economics 7(2), 147-179.

Bound, J., Jaeger, D.A., Baker, R., 1995. Problems with instrumental variables estimation when the correlation between the instruments and the endogenous explanatory variables is weak, Journal of the American Statistical Association 90, 443-450.

Dana, J.D., 1999. Equilibrium price dispersion under demand uncertainty: the roles of costly capacity and market structure, Rand Journal of Economics 30(4), 632-60.

Desai, P.S., 2001, Quality Segmentation in Spatial Markets: When does cannibalization affect product line design?, Marketing Science 20, 265-283.

Dessein, W., 2003. Network competition in nonlinear pricing, Rand Journal of Economics, 34(4): 593-611.

Dresner, M., Lin, J.-S.C., Windle, R., 1996. The impact of low-cost carriers on airport and route competition. Journal of Transport Economics and Policy 30(3), 309-328.

Ellison, G., 2005. A model of add-on pricing. Quarterly Journal of Economics, 120: 585-637.

Escobari, D., Gan, L., 2007. Price dispersion under costly capacity and demand uncertainty. NBER Working Paper No. W13075.

Evans,W.N., Kessides, I.N., 1993. Localized market power in the U.S. airline industry. Review of Economics and Statistics 75 (1), 66-75.

Franke M, 2004, Competition between network carriers and low-cost carriers-retreat battle or breakthrough to a new level of efficiency?, Journal of Air Transport Management, 10: 15-21. 
Gerardi, K., Shapiro, H, A., 2009, Does Competition Reduce Price Dispersion? New Evidence from the Airline Industry, Journal of Political Economy 117, 1-37.

Giaume, S., Guillou, S, 2004. Price discrimination and concentration in European airline markets, Journal of Air Transport Management 10: 305-310.

Goolsbee, A., Syverson, C., 2008, How do incumbents respond to the threat of entry? Evidence from the major airlines, Quarterly Journal of Economics 123(4), 1611-33.

Hernandez, M.A., Wiggins, S.N., 2009. Nonlinear pricing strategies and market concentration in the airline industry, mimeo.

Holmes, T.J., 1989. The effects of third-degree price discrimination in oligopoly, American Economic Review 79(1), 244-50.

Justin, J., Myatt, D., 2003. Multiproduct quality competition: fighting brands and product line pruning, American Economic Review, 93(3):748-774.

Katz, M.L., 1984. Firm-specific differentiation and competition among multiproduct firms, Journal of Business 57, S149-S166.

Katz, E., Spiegel, U., 1996. Negative intergroup externalities and market demand, Economica 63, 513-19.

Leibenstein, H., 1950. Bandwagon, snob, and Veblen effects in the theory of consumers' demand, Quarterly Journal of Economics 64, 183-207.

Liu, Q., Serfes, K., 2006. Second-degree price discrimination and price dispersion: the case of the U.S. airline industry, mimeo.

Moorthy, K. S., 1984. Market Segmentation, Self-Selection, and Product Line Design, Marketing Science, 3: 288-307.

Morrison, S.A., 2001. Actual, Adjacent, and Potential Competition. Estimating the Full Effect of Southwest Airlines, Journal of Transport Economics and Policy 35(2), 239-256.

Morrison, S., Winston, C., 1989. Enhancing the performance of the deregulated air transportation system, Brookings Papers: Microeconomics 1989, 61-123.

Mussa, M. and Rosen, M., 1978. Monopoly and Product Quality, Journal of Economic Theory 18, 301-317.

Pauwels K., Srinivasan S., 2004. Who benefits from store brand entry?, Marketing Science 23, 364-390.

Perloff, J. M., V. Y. Suslow, P. J. Seguin. 1996. Higher prices from entry: Pricing of brand-name drugs. Mimeo, University of California, Berkeley, CA. 
Rochet, J.-C., Stole, L.A., 2002. Nonlinear pricing with random participation, Review of Economic Studies 69, 277-311.

Salop, S. C., 1979. Monopolistic competition with outside goods, Bell Journal of Economics 10, 141-156.

Sinclear, R.A., 1995. An empirical model of entry and exit in airline markets, Review of Industrial Organization 10, 541-57.

Staiger, D., Stock, J.H., 1997. Instrumental variables regression with weak instruments, Econometrica 65 : $557-86$.

Stavins, J., 2001. Price discrimination in the airline market: the effect of market concentration, Review of Economics and Statistics 83, 200-202.

Stole, L., 2007. Price Discrimination in Competitive Environments, in Handbook of Industrial Organization III (M. Armstrong, R.H. Porter, eds), Ch. 34.

Talluri, K.T., van Ryzin, G.J., 2005. The theory and practice of revenue management, Springer, New York.

Thomadsen, R., 2005. Product positioning and competition: the role of location in the fast food industry, Marketing Science 26(6), 792-804.

Vickrey, W. S., 1964. Microstatics. Harcourt, Brace and World, New York. Reprinted (with foreword) as: Selection, Spatial Competition and Monopolistic Competition, International Journal of Industrial Organization 17, 953-963.

Villas-Boas, M., Schmidt-Mohr, U., 1999. "Oligopoly with asymmetric information: Differentiation in credit markets,"RAND Journal of Economics 30, 375-396.

Ward, M. B., Shishack, J. P., Perloff, J. M., Harris, J. M., 2002. Effects on the private-label invasion in food industries, American Journal of Agricultural Economics 84, 961-973.

Whinston, M.D., Collins, S.C., 1992. Entry and competitive structure in deregulated airline markets: an event study analysis of People Express, RAND Journal of Economics 23(4), 445-462.

Wilson, R., 1993, Nonlinear Pricing, Oxford University Press, New York.

Windle, R.J., Dresner, M.E., 1995. The short and long run effects of entry on US domestic air routes, Transportation Journal 35(2), 14-25.

Windle, R., Dresner, M., 1999. Competitive responses to low cost carrier entry, Transportation Research Part E 35:59-75. 
Yang, H., Ye, L., 2008. Nonlinear pricing, market coverage, and competition, Theoretical Economics 3, 123153.

Zhao, W., Zheng Y.-S., 2001. A Dynamic Model for Airline Seat Allocation with Passenger Diversion and NoShow, Transportation Science 35(1), 80-98.

Zhang, D., Cooper, W. L., 2005. Revenue Management for Parallel Flights with Customer-Choice Behavior, Operations Research 53(3), 415-431. 


\section{Appendix}

\section{Analysis of four distinct competition cases}

In this Appendix, we will investigate in turn the properties of four cases of competition in the aviation market, viz. monopoly, symmetric duopoly, asymmetric duopoly, and asymmetric oligopoly.

\section{A1. Monopoly analysis}

Proof of Proposition 1. Part a): We analyse the conditions under which profit maximizing prices are given by (9). First note that, when the market $i$ is partially covered, the location of the indifferent consumer of type $i$ is given by $\hat{x}_{i} \in\left(0, \frac{1}{2}\right)$, and when the monopolist position is in 0 , it is given by: $u_{i i}-\sigma_{i} \hat{x}_{i}-p_{i}=0$. Therefore, demand in market $i$ is $2 \mu_{i} \hat{x}_{i}=\left(2 \mu_{i} / \sigma_{i}\right)\left(v+u_{i i}-p_{i}\right)$. When the market $i$ is fully covered, demand in market $i$ is simply $\mu_{i}$. During the analysis we assume that the weak market is partially covered.

There are four cases of interest that we will now to briefly analyse. The first one is that considered in Section 2.2, i.e. full coverage of the strong market and the ICC is binding (case A). The second is when there is partial coverage of the strong market and the ICC is binding (case B). The third is when there is partial coverage of the strong market and the ICC is not binding (case C). Finally, there is the case in which the strong market is covered but the ICC is not binding (case D).

We start by analysing case $C$ and then study the conditions under which we move to case $B$ or $D$, and finally to case A. The problem can be easily tackled without using the Lagrange multiplier approach.

In case $C$ (partial coverage of the strong market and the ICC is slack), the profit maximizing problem is, therefore:

$$
\max 2 \mu\left(u_{11}-p_{F 1}\right) \sigma_{1}^{-1}\left(p_{F 1}-c_{1}\right)+2(1-\mu)\left(u_{22}-p_{F 2}\right) \sigma_{2}^{-1}\left(p_{F 2}-c_{2}\right)
$$

From first-order conditions, we have: $p_{F i}=\frac{1}{2}\left(u_{i i}+c_{i}\right)$, with $i=1,2$. Using (3), it implies that the ICC is slack if and only if : 


$$
u_{22}+u_{11}-2 u_{21}>c_{2}-c_{1}
$$

To be in case $\mathrm{C}$, however, we also need that $M S_{2}<1$ or, in equilibrium, that $u_{22}<\sigma_{2}+c_{2}$, and therefore, that the total utility received by consumers of type 2 is less than the sum of overall costs. Otherwise, i.e. when:

$$
u_{22}>\sigma_{2}+c_{2}
$$

the monopolist will prefer to offer full coverage of the strong market, i.e. to move from case C to case B. Note that, in case B, where the ICC is slack, and there is full coverage of the strong market, the monopolist charges a price $p_{2}^{c o}=u_{22}-\sigma_{2} / 2$, which is sufficient to extract all the utility from the farthest consumer of type 2 in the strong market, and $p_{F 1}=\frac{1}{2}\left(u_{11}+c_{1}\right)$ in the weak market. This case holds until equation (3) is not binding, or: $u_{11}-c_{1}>2\left(u_{21}-c_{1}\right)-\sigma_{2}$. Note that the previous inequality is stronger than (A2) since it can be written as $u_{22}+u_{11}-2 u_{21}>\left(c_{2}-c_{1}\right)+\left(u_{22}-c_{2}-\sigma_{2}\right)$, where the last term is positive due to the full coverage of the strong market. When:

$$
u_{11}-c_{1} \leq 2\left(u_{21}-c_{1}\right)-\sigma_{2}
$$

we are in the case described in Section 2.2 (case A) provided that there is partial coverage of the weak market, i.e.: $0<M S_{1}<1$. Using (6), and remembering that $M=(1-\mu) /(2 \mu)$, we obtain therefore that:

$$
M \sigma_{1}<u_{11}-c_{1}<(M+1) \sigma_{1}
$$

Inequalities (A3)-(A5) correspond to assumptions (5)-(7). Case B is analogous to case $A$, when, in inequality (A4), the sign " $\leq$ " is replaced by " $>$ ".

Part b) is in the text.

\section{A2. Symmetric duopoly analysis}

Proof of Proposition 2. Parts a), c)-e) are in the text. Part b) We analyse the case when the ICC is binding (the other case has already been presented in Section 2.3), i.e. when $\Delta=c_{2}-c_{1}+\left(\sigma_{2}-\sigma_{1}\right) / 2>r$. Without loss of generality, we consider the pricing decision of firm $j$. Using (2), the indifferent consumer on 
the arc $i j$ is simply: $\hat{x}=\frac{1}{4}\left(\sigma_{i}+2 p_{k l}-2 p_{j l}\right)$ and the market share of firm $j$ on market $i$ is $2 \hat{x}$. Therefore, the maximization problem of firm $j$, after using (3), is:

$$
\max \mu\left(\frac{1}{2}+\frac{p_{k 1}-p_{j 1}}{\sigma_{1}}\right)\left(p_{j 1}-c_{1}\right)+(1-\mu)\left(\frac{1}{2}+\frac{p_{k 2}-p_{j 1}-r}{\sigma_{2}}\right)\left(p_{j 1}+r-c_{2}\right)
$$

Taking the first-order derivative and imposing symmetry, we obtain equation (13).

Part c): We show it for $\Delta<r$. Using (9) and (11), the price difference between monopoly and duopoly in the strong market is positive if:

$$
u_{11}-c_{1} \leq M \sigma_{1}+2\left(u_{22}-c_{2}\right)-\sigma_{2}
$$

From (7), it follows that (A7) is certainly satisfied if $\left(u_{22}-c_{2}\right)>\left(u_{21}-c_{1}\right)$, or $c_{2}-c_{1}<r$, which is satisfied when $\Delta<r$.

Part d) is clear from the text.

\section{A3. Asymmetric duopoly analysis}

The indifferent consumers of type $t_{11}$ and $t_{10}$ are simultaneously obtained by solving the following system:

$$
\left\{\begin{array}{c}
\left(t_{1}+2 \beta\left(\hat{x}_{11}-\hat{x}_{10}\right)\right) q_{1}-\sigma_{1} \hat{x}_{11}-p_{F 1}=\left(t_{1}-2 \beta\left(\hat{x}_{11}-\hat{x}_{10}\right)-\delta_{1}\right) q_{1}-\sigma_{1}\left(1-\hat{x}_{11}\right)-p_{L} \\
t_{1} q_{1}-\sigma_{1} \hat{x}_{10}-p_{F 1}=t_{1} q_{1}-\sigma_{1}\left(1-\hat{x}_{10}\right)-p_{L}
\end{array}\right.
$$

We obtain: $\hat{x}_{10}=\frac{1}{4}-\frac{1}{2 \sigma_{1}}\left(p_{F 1}-p_{L}\right)$ and $\hat{x}_{11}=\frac{1}{4}-\frac{1}{2 \sigma_{1}}\left(p_{F 1}-p_{L}\right)+\frac{q_{1} \delta_{1}}{2 \sigma_{1}-4 \beta q_{1}}$.

Now, the profit maximization of the FSC is given by:

$$
\max \mu\left(\hat{x}_{10}+\hat{x}_{11}\right)\left(p_{F 1}-c_{1}\right)+(1-\mu)\left(p_{F 2}-c_{2}\right)
$$

where $p_{F 2}=p_{F 1}+\left(t_{2}+2 \beta\left(\hat{x}_{11}-\hat{x}_{10}\right)\right)\left(q_{2}-q_{1}\right)$ is the ICC. Note that, although we are considering a situation where LCCs have no direct impact on the strong market, prices in the strong market are, however, 
affected by two channels. First, due to the ICC, $p_{F 2}$ is linked to $p_{F 1}$ : and second, $p_{F 2}$ is also affected by $\left(\hat{x}_{11}-\hat{x}_{10}\right)$, depending on the price choice of the LCC.

The profit maximization of the LCC is given by:

$$
\max \mu\left(1-\left(\hat{x}_{10}+\hat{x}_{11}\right)\right)\left(p_{L}-c_{0}\right)
$$

Taking the first-order derivatives, we obtain the equilibrium prices reported in (15) and (16). Note that the equilibrium prices when the ICC is slack are given by (16) with $M=0$ in the weak market and $p_{2}=u_{22}-$ $\sigma_{2} / 2$ in the strong market. Substituting the previous expressions in (3), after some computations we find that the ICC is binding when:

$$
\sigma_{1}-2 \sigma_{2}-\frac{2}{3}\left(c_{1}-c_{0}\right)+\frac{1}{3}\left(\sigma_{1}-6 \beta q_{1}\right) I \leq 2\left(u_{21}-c_{1}\right)-\sigma_{2}
$$

where $I=\left(\delta_{1} \sigma_{1} q_{1}\right) /\left(\sigma_{1}-2 \beta q_{1}\right)$. Under (7), this restriction is always satisfied exept when $I$ is very large, a case we exclude from our analysis.

Proof of Proposition 3. Part a) of the proposition directly follows from previous discussion. Part b) directly follows by comparing (9) and (16).

In order to prove part c), we compute the price difference $\Delta p_{F 1}\left(\Delta p_{F 2}\right)$ between the monopoly and the asymmetric duopoly case in the weak (strong) market. Using (9) and (16), we obtain:

$$
\begin{aligned}
& \Delta p_{F 1}=-\frac{1}{3}\left(c_{1}-c_{0}\right)-\frac{1}{2}\left(u_{11}-c_{1}-(M+1) \sigma_{1}\right)+\frac{5}{6} M \sigma_{1}+\frac{1}{6} I, \\
& \Delta p_{F 2}=-\frac{1}{3}\left(c_{1}-c_{0}\right)-\frac{1}{2}\left(u_{11}-c_{1}-(M+1) \sigma_{1}\right)+\frac{5}{6} M \sigma_{1}+\frac{1}{6} I+\frac{\beta}{\sigma_{1}} I\left(q_{2}-q_{1}\right) .
\end{aligned}
$$

The first term is non-positive by assumption. The second term is positive by condition A2. Finally, the last two/three terms are positive. Therefore, the price difference can be simultaneously negative in the weak market and positive in the strong market if:

$$
\frac{1}{6} I<\frac{1}{3}\left(c_{1}-c_{0}\right)-\frac{1}{2}\left(u_{11}-c_{1}-(M+1) \sigma_{1}\right)-\frac{5}{6} M \sigma_{1}<\frac{1}{6} I+\beta I\left(q_{2}-q_{1}\right) / \sigma_{1}
$$


i.e. the cost differentials are sufficiently high.

\section{A4. Asymmetric oligopoly analysis}

Consider the three regions of the circumference as separated by the three carriers: $A \equiv\left(0, \frac{1}{4}\right), B \equiv\left(\frac{1}{4}, \frac{1}{2}\right)$ and $C \equiv\left(\frac{1}{2}, 1\right)$. Due to the presence of LCCs, $t_{11}$-type and $t_{10}$-type consumers located in the same place may prefer to patronize different carriers. Using equations (1) and (2), the utility that a $t_{11}$-type traveller located in $x \in A \equiv\left(0, \frac{1}{4}\right)$ receives when patronizing the FSC $F_{A}$ is: $v+\left(t_{1}+\beta\left(x_{A 11}-x_{A 10}\right)-\right.$ $\beta x C 11-x C 10 q 1-\sigma 1 D x, y A-p A 1$, and the utility she receives when patronizing the LCC is: $v+\left(t_{1}-\beta\left(x_{A 11}-x_{A 10}\right)+\beta\left(x_{B 11}-x_{B 10}\right)-\delta\right) q_{1}-\sigma_{1} D\left(x, y_{L}\right)-p_{L}$, where $x_{A 11}$ and $x_{A 10}$ are, respectively, the number of $t_{11}$-type and $t_{10}$-type passengers travelling with the FSC $F_{A}$ on the arc $A \equiv\left(0, \frac{1}{4}\right)$, and analogously for $x_{B 11}, x_{B 10}, x_{C 11}$ and $x_{C 10}$. Similarly, the utility that a $t_{11}$-type traveller located in $x \in B \equiv\left(\frac{1}{4}, \frac{1}{2}\right)$ receives when patronizing the FSC $F_{B}$ is: $v+\left(t_{1}-\beta\left(x_{B 11}-x_{B 10}\right)+\right.$ $\beta x C 11-x C 10 q 1-\sigma 1 D x, y B-p B 1$, and the utility she receives when patronizing the LCC is: $v+\left(t_{1}-\beta\left(x_{A 11}-x_{A 10}\right)+\beta\left(x_{B 11}-x_{B 10}\right)-\delta\right) q_{1}-\sigma_{1} D\left(x, y_{L}\right)-p_{L}$. Finally, the utility that a $t_{11}$-type traveller located in $x \in C \equiv\left(\frac{1}{2}, 1\right)$ receives when patronizing the FSC $F_{A}$ is: $v+\left(t_{1}+\beta\left(x_{A 11}-x_{A 10}\right)-\right.$ $\beta x C 11-x C 10 q 1-\sigma 1 D x, y A-p A 1$, and when patronizing the FSC $F B$ is: $v+\left(t_{1}-\beta\left(x_{B 11}-x_{B 10}\right)+\beta\left(x_{C 11}-x_{C 10}\right)\right) q_{1}-\sigma_{1} D\left(x, y_{B}\right)-p_{B 1}$. The utility of $a t_{10}$-type consumer is as previously described by imposing $\beta=0$.

Using the previous expressions and solving for the indifferent consumer, after some computations, it is possible to derive the market shares of the three firms as a function of the three prices, and, after substituting them in the profit functions and solving a 3-equation system of the first order conditions, we obtain the equilibrium prices reported in equations (13) and (14).

Proof of Proposition 4. Part a) of the proposition directly follows from the previous discussion. Part b) holds since in the asymmetric duopoly the ICC is binding, while in the asymmetric oligopoly it is not. In 
order to prove part c), we compute the price difference $\Delta p_{F 1}$ between the asymmetric oligopoly case and the symmetric duopoly case in the weak market. Using (11) and (18), we obtain:

$$
\Delta p_{F 1}=-\frac{1}{5}\left(c_{1}-c_{0}\right)-\frac{3}{20} \sigma_{1}+\frac{1}{5} \frac{\delta \sigma_{1} q_{1}}{2 \sigma_{1}-3 \beta q_{1}} .
$$

Here there are two sources of price reduction. The first is due to the cost advantage of the LCCs, which induces the FSCs to reduce their prices; the second is due to proximity of the LCC, which induce more competition. Inter-group effects play in the opposite direction. Since $p_{F 2}$ remains unchanged $\left(\Delta p_{F 2}=0\right)$, conditions their guaranteeing a price fall in the weak market are also those that imply an increase in price differences when moving from a symmetric duopoly to an asymmetric duopoly. 